\title{
Pulmonary Pathological Features in Viraemia Associated Secondary Lung Injury
} \author{
Sona Hakobyan ${ }^{1 *}$ \\ ${ }^{1}$ Laboratory of Cell Biology and Virology, Institute of Molecular Biology of NAS RA, Armenia \\ ${ }^{2}$ Yerevan State Medical University, Armenia \\ ${ }^{3}$ Experimental laboratory, Yerevan State Medical University, Armenia
}

Hranush Arzumanyan ${ }^{1}$, Tigran Mezhlumyan² ${ }^{2}$ Nazeli Gevorgyan² ${ }^{2}$ Alexander Karalyan² ${ }^{2}$ Aida Avetisyan ${ }^{1,3}$ and

Submission: April 23, 2021; Published: May 19, 2021

*Corresponding author: Sona Hakobyan, Laboratory of Cell Biology, Institute of Molecular Biology of NAS RA, Armenia

\section{Abstract}

Both African swine fever virus (ASFV) and Rabbit hemorrhagic disease virus (RHDV) are important pathogens in veterinary. ASFV causes African swine fever (ASF) in pigs and RHDV causes rabbit hemorrhagic disease (RHD) in rabbits. Secondary lung pathology was investigated for these diseases as one of the consequences of viraemia. Rabbits and pigs were taken for the observation of these diseases. Imprint smears of the lungs, lung tissue and blood samples from intact and infected animals were taken for the exploration. Afterwards, some observations were done for each animal: histopathological analysis of lungs, bronchoalveolar lavage (BAL) cell population counting and detection of serum TNF-alpha, IFN-gamma and NO levels. Histopathological analysis showed many hemorrhages in lung tissue. BAL analysis presented significant changes in cell population. Serum levels of TNF-alpha, IFN-gamma and NO were increased. From the results can be concluded, that there are many similarities in the secondary lung pathology for these viruses and the main mechanism of lung tissue pathology is the high vascular permeability caused by changes in cytokines and NO levels.

Keywords: African swine fever virus; Rabbit hemorrhagic disease virus; BAL cells; Lung pathology; Hemorrhages

Abbreviations: BAL: Broncoalveolar Lavage; AM: Alveolar Macrophages; ASFV: African Swine Fever Virus; RHDV: Rabbit Hemorrhagic Disease Virus; DPI: Days Post Infection; DIC: Disseminated Intravascular Coagulation

\section{Introduction}

African swine fever virus (ASFV) is a double-strained DNA virus and is classified as the only member of the family Asfarviridae. ASFV causes African swine fever (ASF) which is one of the most important threats in pig breeding and wild boar populations because of high mortality [1-3]. The replication of ASFV takes place mainly in monocytes and macrophages [4]. Proinflammatory cytokines (ILs, TNF- alpha, IFN- gamma) and NO produced by infected monocytes and macrophages are playing an important role in the pathogenesis of this disease causing an immoderate inflammatory response and inducing the apoptosis of macrophages and lymphocytes [5,6]. The consequences are hemorrhages in various organs.

Rabbit hemorrhagic disease virus (RHDV) is a linear positivesense RNA virus of family Caliciviridae [7]. RHDV causes the rabbit hemorrhagic disease (RHD), also known as rabbit plague. RHD is characterized by necrotizing hepatitis, but hemorrhages may also can be detected in other organs, particularly in the lungs, heart and kidneys [8]. In earlier studies it was presented that the host cells for RHDV are hepatocytes and mononuclear phagocytes [9]. As well as for ASFV, it was shown serum levels elevation of TNF-alpha and IFN-gamma for RHDV [7].

The predominant pathological findings in lung injury caused by investigated viruses are lung hemorrhages. These severe pulmonary injuries of investigated animals can be caused both by direct viral effects by abnormal immune response [6,8]. Till now many important aspects of the lung pathology and pathogenesis of ASF and RHD have not yet been fully clarified. The goal of this study was to investigate effect of RHDV and ASFV on host lungs by analysis of bronchoalveolar lavage cell populations, 
histopathologic observation of lung tissues and examination of serum levels of NO, TNF-alpha and IFN-gamma. The mechanisms of lung pathologies in both the diseases are also being compared.

\section{Methods}

\section{Viruses}

For the investigations it was used ASFV (genotype II) distributed in the Republic of Georgia and the Republic of Armenia. Infectious titer of ASFV was calculated by the method of haemadsorption [10]. RHDV was obtained from Agricultural University of Armenia. The virus sample was prepared from infected rabbit livers. HA test and PCR was used for routine diagnosis of RHD [11]. The hemagglutination test was performed according to Nystrom et al. [12].

\section{Animals}

15 pigs of the same age ( 3 months old) and weight (30$32 \mathrm{~kg})$ were used for infection $(\mathrm{n}=12)$ and as controls $(\mathrm{n}=3)$. The animals were housed in separate stables, where they had access to a commercial feed twice per day and to clear water at all times. Pigs were intramuscularly inoculated in the hip with $5 \mathrm{ml}$ of 104 $50 \%$ hemadsorbing doses (HAD50)/ml doses of the Georgia 2007 isolate. Nine $(n=9)$ pigs were used for tissue sampling and cell analysis, whereas three other pigs $(n=3)$ were used to collect blood and cytokine experiments. The viral titer in sera was determined by hemadsorption microtest and expressed as log $10 \mathrm{HAD} 50 / \mathrm{ml}$.

Twelve rabbits (Oryctolaguscuniculus), 6 months old with an average weight of $2.0 \mathrm{~kg}$, were purchased from a conventional rabbitry. All rabbits were RHDV-negative. Absence of RHDV antibodies in rabbit blood sera was demonstrated by hemagglutination inhibition test, and PCR reaction. Nine rabbits were inoculated intramuscularly with $1 \mathrm{ml}$ each of a $10 \%$ liver homogenate, and 3 rabbits served as control [13].

\section{Imprint smears and $\mathrm{AM}$ number}

Imprint smears were obtained from the fresh cut surface of lung after autopsy, fixed routinely in 95\% ethanol, and then stained using the Papanicolaou technique. The imprint smear slides $(n=5)$ in each case were examined by 3 observers and assessed for the number of macrophages per field $70 \times 54 \mu \mathrm{m}$. In each examination were observed 100 fields. Active AM were detected using following criteria: increased phagocytosis, vacuolization of the cytoplasm and arising of pseudopodia [14].

\section{Histopathology}

Tissue samples of buffered formalin fixed lungs were dehydrated, embedded in paraffin wax, sectioned at $5 \mu$ m, and stained with haematoxylin and eosin for microscopic evaluation.

\section{Cytokine analysis}

From 1 to 3 days post infection (dpi), blood samples were collected from the ophthalmic venous sinuses of pigs as described by Stier and Leuch19. In rabbit preinoculation (0 dpi) blood samples were taken as control values. Blood samples were drawn by heart puncture in each case from 3 rabbits. ELISA method was used to detect the serum levels of TNF-alpha, IFN-gamma in the culture supernatants (Mybiosource). The levels of cytokines (pg/ $\mathrm{ml}$ ) were measured using a colorimetric reader (Stat Fax 303 Plus) and were calculated according to the cytokine standard curve supplied in the kits. All samples were tested in duplicate according to manufacturers' instructions.

\section{Determination of NO}

Griess method was used for determining NO levels. 1\% Sulfanilamide in 5\% H3PO4 (aqueous) and 1\% N-naphthylethylenediamine (aqueous) was premixed to form a $200 \mu \mathrm{l}$ NO production was evaluated by a colorimetric assay for the nitrite metabolite based on the Griess reaction. Minor changes were made to the common procedure. Briefly, on $1.5 \mathrm{ml}$ of deoxygenated distillated water $200 \mu \mathrm{l}$ of supernatant was reacted in a mixture of $100 \mu \mathrm{l}$ of $0.1 \% \mathrm{~N}$-naphthyl-ethylenediaminedihydrochloride (NED) and $100 \mu$ l of $1.0 \%$ sulphanilamide in $5.0 \%$ phosphoric acid at room temperature. The 2 parts were mixed within $12 \mathrm{~h}$ of use and kept chilled $\left(+4^{\circ} \mathrm{C}\right)$. The absorbance was read after 15 minutes in a spectrophotometer at $540 \mathrm{~nm}$ with reference to a standard nitrite quantitative curve with a maximum concentration of $3 \mathrm{~mm}$. Deoxygenated distillated water was used to avoid nitrite oxidation.

\section{Statistical analysis}

All experiments were repeated 3 times and statistical analyses were performed using the Student's t test. SPSS version 13.0 software package (SPSS Inc., Chicago, IL, USA) was used for statistical analyses.

\section{Results}

\section{Lung histopathology}

Experimental animals were infected by intramuscular injection by viruses (ASFV and RHDV). In both cases were observed standard course of the diseases; fever commenced several hours after the viraemia which were detected after 24 hours post infection (hpi). Lung pathology investigated in 72hpi.

As shown in (Table 1), after the viraemia significantly increased the amount of lymphocytes and neutrophils in bronchoalveolar lavage (BAL). Both infections ASFV (at 3-5dpi) and RHDV (at 2-3dpi) caused pulmonary hemorrhage. By RHDV hemorrhages in lung tissue were more prominent and intensive (Figure 1A) compared to ASFV induced lesions (Figure 1B).

After 48-72 hpi BAL investigation showed intense alveolar inflammation, with recruitment of inflammatory cells, predominantly lymphocytes and neutrophils (Table 1, Figure 1C \& 1D). Also, were observed massive diapedesis of erythrocytes, neutrophils, and lymphocytes in lung tissue of infected rabbits 
(Figure 1C \& 1E). These processes were accompanied by increased number of all types of cells in alveolar cavities of pigs (Figure 1D \&
1F). All above mentioned suggest an increase in the permeability of the wall of the alveoli.

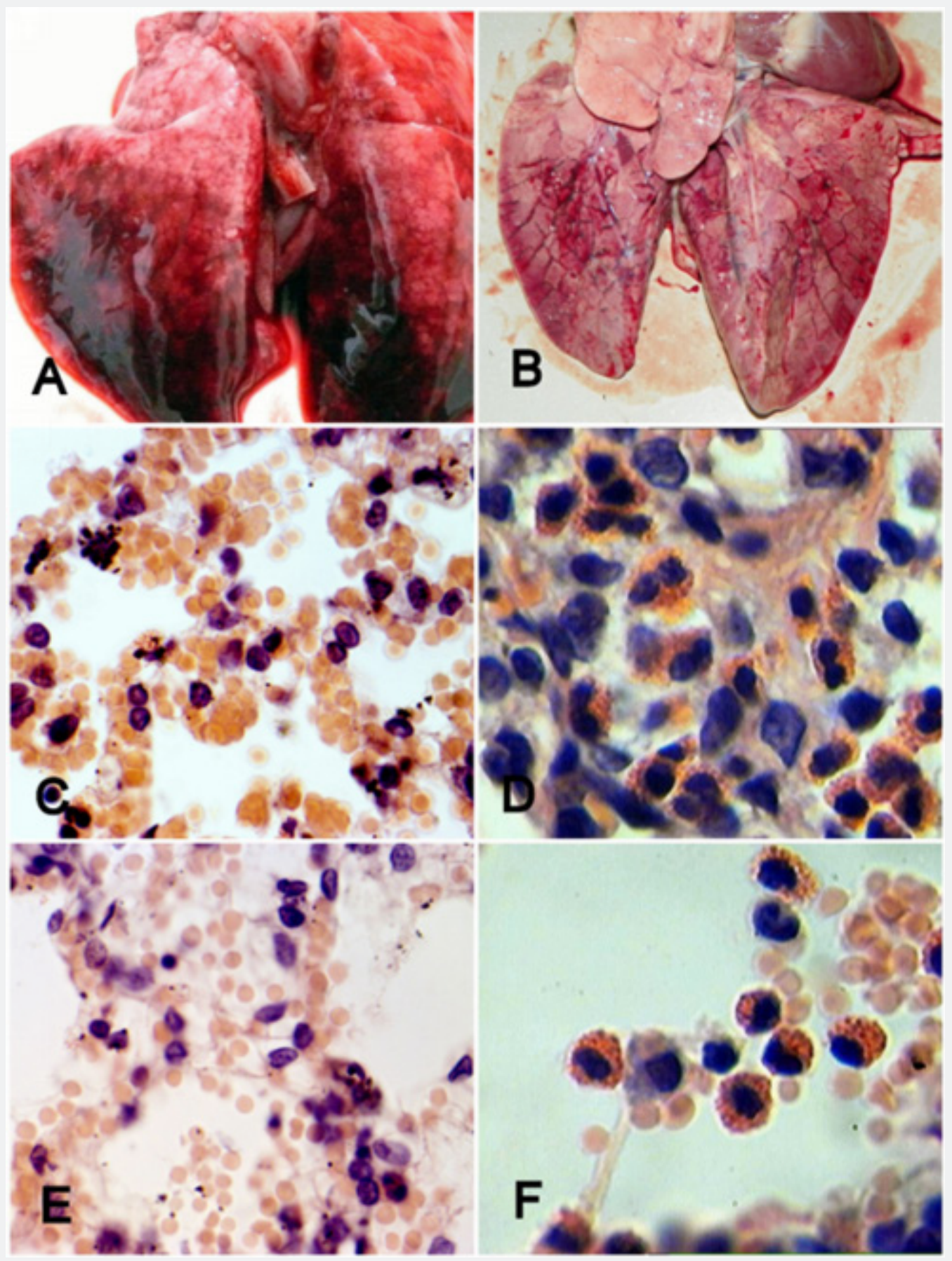

Figure 1: Pathoanatomical changes in rabbit and porcine lungs. A. Areas of massive hemorrhages on the inferior surface of rabbit lungs under the influence of RHDV; 3 dpi. B. Areas of hemorrhages in porcine lungs under the influence of ASFV; 3 dpi. C. Erythrocyte diapedesis in rabbit lungs under the influence of RHDV; $3 \mathrm{dpi}$, alveolar macrophage with RHDV inclusions (arrowed). D. Myeloid cells' diapedesis in porcine lungs under the influence of ASFV; $3 \mathrm{dpi}$. E. Diapedesis and presence of erythrocytes in the alveolar cavity in rabbit lungs under the influence of RHDV; 3 dpi. F. Myeloid cells and erythrocytes in the alveolar cavity in porcine lungs under the influence of ASFV; 3 dpi. 
Table 1: Main populations of BAL cells in healthy and infected animals.

\begin{tabular}{|c|c|c|c|c|}
\hline Cells & Pig Control & ASFV Infected Pigs (3 dpi) & Rabbit Control & RHDV Infected Rabbit (3 dpi) \\
\hline $\mathrm{AM}(\%)$ & $76.4 \pm 8.1$ & $62.6 \pm 9.3$ & $86.6 \pm 9.3$ & $66.4 \pm 5.9$ \\
\hline Lymphocyte (\%) & $10.1 \pm 0.7$ & $21.0 \pm 5.1^{*}$ & $7.0 \pm 1.0$ & $19.2 \pm 4.7^{*}$ \\
\hline Neutrophil (\%) & $8.0 \pm 1.1$ & $12.8 \pm 2.1^{*}$ & $3.3 \pm 0.5$ & $11.1 \pm 3.2^{*}$ \\
\hline Eosinophil (\%) & $4.7 \pm 0.2$ & $3.5 \pm 0.4$ & $3.1 \pm 0.4$ & $3.9 \pm 0.8$ \\
\hline Other $(\%)$ & $0.8 \pm 0.1$ & $0.1 \pm 0.1$ & $>0.2 \pm 0.1$ & $0.4 \pm 0.1$ \\
\hline
\end{tabular}

*Significant, compared to control ( $p>0.05)$.

\section{Cytokines levels in serum}

It has been detected, that viraemia in both cases (RHDV and ASFV) was associated with increased levels of IFN gamma (Figure $2 \mathrm{~A} \& 2 \mathrm{~B}$ ) and TNF alpha (Figure 2C \& 2D) in serum of infected rabbits as well as pigs.

It can be seen from (Figure 2A), that Rabbit IFN-gamma levels has been elevated since 1 st dpi. The same results have been detected for Porcine IFN-gamma levels (see Figure 2B). In case of Rabbit TNF-alpha levels, it has been evaluated elevation since 2nd dpi andin case of Porcine TNF-alpha levels has been increased since $1 \mathrm{st}$ dpi. Thus, in all cases significant changes has been detected compared with control/ $0 \mathrm{dpi}$.

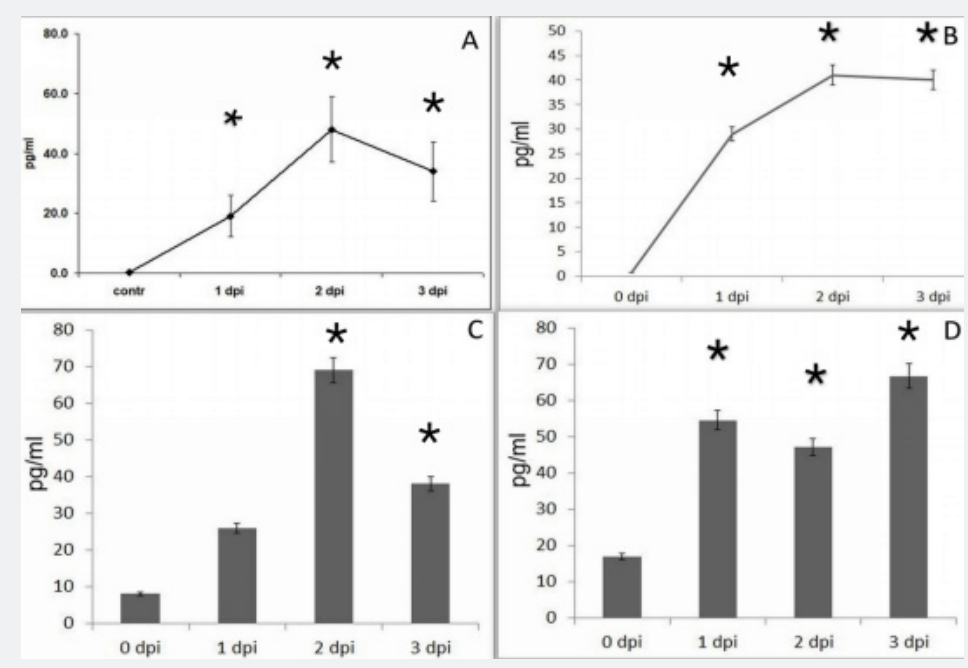

Figure 2: Cytokines levels in rabbit and porcine serum.

A. Rabbit IFN-gamma levels; B. Porcine IFN-gamma levels; C. Rabbit TNF-alpha levels; D. Porcine TNF-alpha levels. *Significantly compared with healthy animals $(p>0.05)$.

\section{Nitric oxide}

Our study demonstrated that both in rabbits and in pigs with the viraemia were observed significantly higher serum levels of NO than in healthy animals (Figure 3). According to our results, serum levels of nitric oxide have been increased in both cases of diseases. Furthermore, in infected rabbits' elevation was detected since 1 st dpi, and in infected pigs since 2nd dpi (see Figure 3).

\section{Discussion}

It has been shown above gross postmortem findings revealed lung hemorrhages. The hemorrhages, diapedesis and the increase in the lymphocyte and neutrophil amount in BAL indicate the development of significant pulmonary pathology. In both infections, the lungs do not become the primary target for viral infections but are susceptible to secondary viral invasions 
resulting from the viremia $[6,8]$. The cells of the mononuclear phagocyte system are involved in the pathogenesis of RHD and
ASF, and a significant role are playing proinflammatory cytokines and NO produced by these cells.

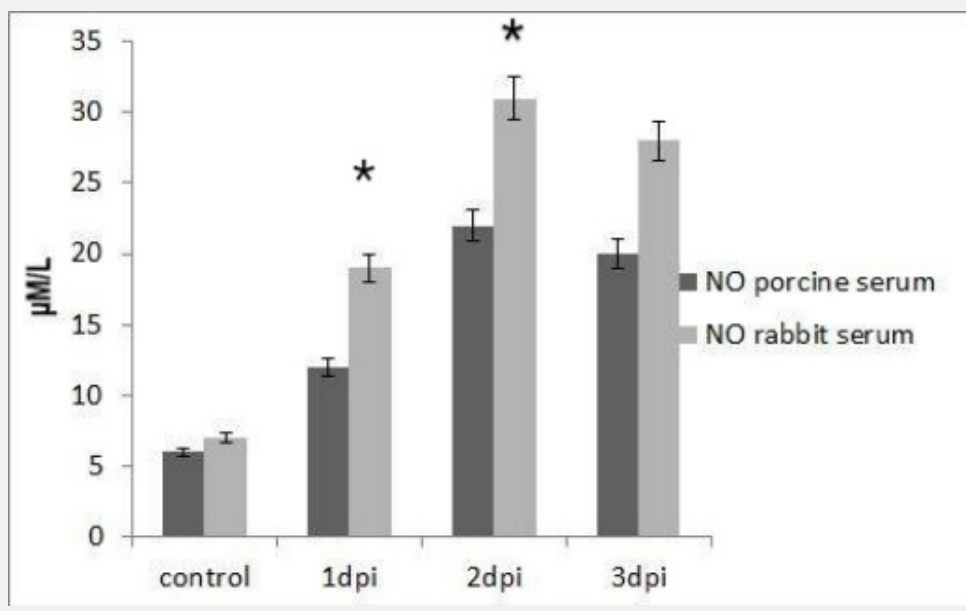

Figure 3: Serum levels of nitric oxide in infected pigs and rabbits. *Significantly compared to healthy animals $(p>0.05)$.

Data of Trzeciak-Ryczek et al. [15] and Semerjyan et al. [7] for both ASFV and RHDV it was shown increase of serum TNFalpha and IFN-gamma levels. In our research we detected similar results: starting from 1 dpi there are significantly high TNFalpha and IFN-gamma concentrations in serum. Furthermore, we have found increased serum NO levels since the $1 \mathrm{dpi}$ in both cases. IFN-gamma has antiviral activity and chemotactic effect on monocytes/macrophages [16]. It induces the synthesis of TNFalpha contributing its high levels [15]. TNF-alpha is considered to be the main mediator of programmed cell death [17].

It induces the apoptosis of uninfected lymphocytes in ASFVinfected pigs causing lymphopenia and severe impairment of lymphoid organs [18], and in hepatocytes of RHDV-infected rabbits leading to liver damage and dysfunction [19]. Also, it is wellknown that TNF-alpha is an important mediator in the regulation of endothelial permeability [20]. TNF-alpha causes vasodilation, increases the vascular permeability, leads to elevation of the tissue factor expression and detraction of trombomodulin expression thereby inducing indirectly disseminated intravascular coagulation (DIC) [16]. The severe liver necrosis in RHD is also a contributing factor in the manifestation of DIC.

In past research it was shown that high NO levels have role in increasing of permeability of capillaries. From this fact it seems that the path of pathogenesis in lungs is similar for both viruses. Probably the high NO level is side effect of the macrophage striving against virus-NO is one of the mediators in intracellular inhibition of viral replication. From recent studies we know for ASF that NO elevates the endothelial permeability mediated by vascular endothelial growth factor [6]. It seems that this mechanism of a diapedesis exists for RHD too.
The lung pathology is similar in both diseases and is presented with diapedesis. We can surely affirm that some pathological mechanisms resemble as follows: vascular permeability mediated by TNF-alpha and also probably by NO-stimulated VEGF, target cells apoptosis and disseminated intravascular coagulation causing hemorrhages [6-8,19,20]. Another common feature is the high concentration of IFN-gamma. For RHD an additional contributing factor in the lung pathology is the liver necrosis [19]. So, we can conclude that lung pathology seen in animals with both viruses shows marked microvascular thrombosis and hemorrhage linked to extensive alveolar, diapedesis and interstitial inflammation that shares features with macrophage activation syndrome.

\section{Conclusion}

From the results can be concluded, that there are many similarities in the secondary lung pathology for these viruses and the main mechanism of lung tissue pathology is the high vascular permeability caused by changes in cytokines and NO levels.

\section{Ethical Statement}

All animal experiments were permitted by the Institutional Review Board/Independent Ethics Committee of the Institute of Molecular Biology of NAS RA (reference number IRB00004079).

\section{References}

1. Sanchez CPJ, Alejandro N, Aleksija N, Emil WL, Maria M, et al. (2019) African swine fever: Disease dynamics in wild boar experimentally infected with ASFV isolates belonging to genotype I and II. Viruses 11(9): 852.

2. More S, Miguel AM, Dominique B, Anette B, Andrew B, et al. (2018) African swine fever in wild boar. EFSA Journal 16(7): e05344. 
3. Authie E, Berg C, Anette B, Howard B, Ilaria C, et al. (2014) Scientific Opinion on African swine fever. EFSA Journal 12(4): 3628.

4. Wardley RC, Hamilton F, Wilkinson PJ (1979) The replication of virulent and attenuated strains of African swine fever virus in porcine macrophages. Arch Virol 61(3): 217-225

5. Ramiro IF, Ortega A, Brun A, Escribano JM, Alonso C (1996) Apoptosis: a mechanism of cell killing and lymphoid organ impairment during acute African swine fever virus infection. J Gen Virol 77(Pt 9): 22092219.

6. Tatoyan MR, ZRT Pogossyan, AB Semerjyan, VS Gevorgyan, NY Karalyan, et al. (2019) Serum Concentrations of Vascular Endothelial Growth Factor, Stromal Cell-Derived Factor, Nitric Oxide and Endothelial DNA Proliferation in Development of Microvascular Pathology in Acute African Swine Fever. J Comp Pathol 167: 50-59.

7. Semerjyan $A B$, Mariam AS, Hranush HA, Lina HH, Liana OA, et al. (2019) Immune cell pathology in rabbit hemorrhagic disease. Vet World 12(8): 1332-1340.

8. Abrantes J, Vander LW, Le Pendu J, Esteves PJ (2012) Rabbit haemorrhagic disease (RHD) and rabbit haemorrhagic disease virus (RHDV): a review. Vet Res 43(1): 12.

9. Ramiro IF, Martin AJM, Garcia PP, Parra F, Alonso C (1999) Macrophage tropism of rabbit hemorrhagic disease virus is associated with vascular pathology. Virus Res 60(1): 21-28.

10. Enjuanes L, Carrascosa AL, Moreno MA, Vinuela E (1976) Titration of African swine fever (ASF) virus. J Gen Virol 32(3): 471-477.

11. Kimura T, Mitsui I, Okada Y, Furuya T, Ochiai K, et al. (2001) Distribution of rabbit haemorrhagic disease virus RNA in experimentally infected rabbits. J Comp Pathol 124(2-3): 134-141.

12. Nystrom K, Le Gall RG, Paola Grassi, Joana A, Nathalie RC, et al.
(2011) Histo-blood group antigens act as attachment factors of rabbit hemorrhagic disease virus infection in a virus strain-dependent manner. PLoS Pathog 7(8): e1002188.

13. Mc Intosh MT, Behan SC, Mohamed FM, Lu Z, Moran KE, et al. (2007) A pandemic strain of calicivirus threatens rabbit industries in the Americas. Virol J 4: 96.

14. Petricevich VL, Reynaud E, Cruz AH, Possani LD (2008) Macrophage activation, phagocytosis and intracellular calcium oscillations induced by scorpion toxins from Tityus serrulatus. Clin Exp Immunol 154(3) 415-423.

15. Trzeciak RA, Tokarz DB, Deptula W (2017) Expression of IL-1Ra, IL-6 IL-8, IL-18, TNF- $\alpha$ and IFN- $\gamma$ genes in peripheral blood leukocytes of rabbits infected with RHDV (Rabbit Haemorrhagic Disease Virus). Dev Comp Immunol 76: 310-315.

16. Akdis M, Burgler S, Reto C, Thomas E, Hiroyuki F, et al. (2011) Interleukins, from 1 to 37, and interferon- $\gamma$ : receptors, functions, and roles in diseases. J Allergy Clin Immunol 127(3): 701-721.

17. Antoniades CG, Berry PA, Wendon JA, Vergani D (2008) The importance of immune dysfunction in determining outcome in acute liver failure. J Hepatol 49(5): 845-861.

18. Gomez VJC, Hervas J, Mendez A, Carrasco L, Martin Delas MJ, et al. (1995) Experimental African swine fever: apoptosis of lymphocytes and virus replication in other cells. J Gen Virol 76(Pt 9): 2399-2405.

19. Alonso C, Oviedo JM, Martin AJM, Diaz E, Boga JA, et al. (1998) Programmed cell death in the pathogenesis of rabbit hemorrhagic disease. Arch Virol 143(2): 321-332.

20. Gomez Del MM, Ortuno E, Fernandez ZP, Alonso F, Alonso C, et al (1999) African swine fever virus infection induces tumor necrosis factor alpha production: implications in pathogenesis. J Virol 73(3): 2173-2180.

\section{Your next submission with Juniper Publishers will reach you the below assets}

- Quality Editorial service

- Swift Peer Review

- Reprints availability

- E-prints Service

- Manuscript Podcast for convenient understanding

- Global attainment for your research

- Manuscript accessibility in different formats ( Pdf, E-pub, Full Text, Audio)

- Unceasing customer service

Track the below URL for one-step submission https://juniperpublishers.com/online-submission.php 